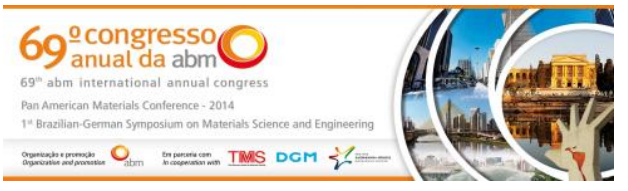

Tema: Iniciação científico-tecnológica

\title{
ESTUDO DO COMPORTAMENTO ELETROQUÍMICO DO AÇO UNS S31803 ENVELHECIDO A 700ㄷ POR ENSAIOS DE REATIVAÇÃO POTENCIODINÂMICA DE DUPLO LOOP (DL-EPR)*
}

\section{Resumo}

Daniel Hiroshi Taira Anese ${ }^{1}$ Daniella Caluscio dos Santos²

O objetivo desse trabalho consiste no estudo do grau de sensitização do aço UNS S31803 envelhecido a $700^{\circ} \mathrm{C}$ por ensaios de reativação potenciodinâmica de duplo loop (DL-EPR). Para isso corpos de prova do aço em estudo foram solubilizados a $1175^{\circ} \mathrm{C}$ e envelhecidos a $700^{\circ} \mathrm{C}$ em tempos entre $10 \mathrm{~min}$ e $360 \mathrm{~h}$. Corpos de prova metalográficos foram utilizados para caracterização microestrutural que foi realizada por meio de técnicas de estereologia quantitativa a partir de imagens de elétrons retroespalhados e análises magnéticas usando o ferritoscópio. Os ensaios DL-EPR foram conduzidos em solução $2 \mathrm{M} \mathrm{H}_{2} \mathrm{SO}_{4}+0,5 \mathrm{M} \mathrm{NaCl}+0,01 \mathrm{M}$ $\mathrm{KSCN}$ à $30^{\circ} \mathrm{C}$ em amostras polidas. Observou-se que o comportamento eletroquímico do aço UNS S31803 possui forte influência da microestrutura, já que o grau de sensitização (GS) aumenta com o aumento do tempo de envelhecimento, devido à formação de fases intermetálicas que empobrecem as regiões adjacentes em Cr e Mo.

Palavras-chave: Aços inoxidáveis dúplex; Grau de sensitização; Ensaios eletroquímicos; Reativação potenciodinâmica de duplo loop (DL-EPR).

\section{STUDY OF ELECTROCHEMICAL BEHAVIOR OF STEEL UNS S31803 AGED AT $700^{\circ} \mathrm{C}$ BY DOUBLE LOOP POTENTIODYNAMIC REACTIVATION TESTS}

\section{Abstract} (DL-EPR)

The aim of this work is the study of the degree of sensitization of UNS S31803 duplex stainless steel aged at $700^{\circ} \mathrm{C}$ by double loop potentiodynamic reactivation tests (DL - EPR). The samples were solution-treated at $1175^{\circ} \mathrm{C}$ and aged at $700^{\circ} \mathrm{C}$ between 10 minutes and $360 \mathrm{~h}$. The microestructural characterization, was performed by quantitative metalography using backscattered electron images magnetic analysis with a ferritoscope. The DL-EPR tests were conducted in $2 \mathrm{M}$ $\mathrm{H}_{2} \mathrm{SO}_{4}+0,5 \mathrm{M} \mathrm{NaCl}+0,01 \mathrm{M}$ KSCN solution at $30^{\circ} \mathrm{C}$ in polished samples. It was observed that the electrochemical behavior of UNS S31803 steel is strongly associated relation with microstructure. The degree of sensitization increase with the increase of aging time due to the formation of intermetallic phases that promotes the formation of $\mathrm{Cr}$ an Mo depleted zones.

Keywords: Duplex stainless steel; Degree of sensitization; Eletrochemical tests; double loop potentiodynamic reactivation tests (DL-EPR).

1 Estudante de Engenharia de Materiais, Departamento de Engenharia de Materiais, FEl, São Bernardo do Campo, São Paulo, Brasil.

2 Engenheira Química, Doutora, Professora, Departamento de Engenharia de Materiais, FEI, São Bernardo do Campo, São Paulo, Brasil.

\footnotetext{
* Contribuição técnica ao $69^{\circ}$ Congresso Anual da ABM - Internacional e ao 14ํㅡㄹ ENEMET - Encontro Nacional de Estudantes de Engenharia Metalúrgica, de Materiais e de Minas,21 a 25 de julho de 2014, São Paulo, SP, Brasil.
} 


\section{INTRODUÇÃO}

Aços inoxidáveis dúplex são aços que possuem frações aproximadamente iguais de ferrita e austenita em sua estrutura e apresentam uma boa resistência à corrosão, bem como elevada resistência mecânica. São considerados inoxidáveis por possuírem no mínimo $12 \%$ de cromo em sua estrutura [1], o que permite a formação de película passiva, caracterizada por ser aderente, não porosa e auto-regenerativa. No entanto, quando submetidos a temperaturas entre 600 e $1000^{\circ} \mathrm{C}$ os aços inoxidáveis dúplex podem sofrer transformações de fase no estado sólido formando fases intermetálicas como sigma $(\sigma)$, chi $(\chi)$ e nitretos de cromo $\left(\mathrm{Cr}_{2} \mathrm{~N}\right)$, dependendo da sua composição química [1], que são prejudiciais às suas propriedades. A fase sigma é a mais deletéria dentre as citadas, pois apresenta altas frações volumétricas dependendo do tempo de exposição à temperaturas elevadas. Por ser uma fase extremamente frágil, a formação de sigma reduz a tenacidade do material e por ser rica em $\mathrm{Cr}$ e Mo faz com que sua formação reduza a resistência à corrosão, devido ao empobrecimento das regiões vizinhas à sua formação nesses elementos. São três os principais mecanismos formadores de sigma em aços inoxidáveis dúplex [2]: (a) Decomposição eutetóide da ferrita gerando austenita secundária empobrecida em cromo e molibdênio; b) Nucleação e crescimento a partir da ferrita, formando ferrita secundária empobrecida em cromo e molibdênio; c) Crescimento a partir da austenita após o total consumo de ferrita.

A fase chi é mais rica em Mo em relação à sigma, e sua formação é deletéria em termos de resistência à corrosão do material, muito embora essa fase seja formada em frações volumétricas muito baixas. A formação de nitretos de cromo também leva à diminuição da resistência à corrosão do material pelos mesmos motivos descritos acima das regiões vizinhas à sua formação.

O comportamento eletroquímico dos aços inoxidáveis dúplex possui forte influência da microestrutura [3]. A influência da formação de fases na resistência a corrosão vem sendo muito estudada nos dias atuais. No entanto, ensaios de polarização potenciodinâmica são quase sempre destrutivos e por isso necessitam de quantidades consideráveis de material para realizar os estudos [4]. Da necessidade de realizar ensaios não destrutivos em aços inoxidáveis foi desenvolvido o ensaio de reativação potenciodinâmica de duplo loop (DL-EPR). Essa técnica foi desenvolvida primeiramente para aços inoxidáveis austeníticos e foi baseada na técnica SL-EPR, reativação potenciodinâmica único loop, e foi proposta inicialmente por Majidi e Streicher [5] para detectar sensitização em aços inoxidáveis austeníticos. Os autores destacam as vantagens do ensaio de DL-EPR em comparação com o ensaio SLEPR, dentre elas a melhor reprodutibilidade, além da não necessidade de um acabamento superficial refinado. O ensaio DL-EPR consiste basicamente em polarizar o material a partir do potencial de circuito aberto até a região de passivação, então o ensaio é invertido e a varredura é feita na mesma velocidade pré-determinada de volta ao potencial de circuito aberto [6]. Durante a ativação acontece a formação da película passiva, então a inversão é feita de modo que a amostra ainda apresente tal película. No entanto, na reativação ocorre a quebra parcial da película passiva, que pode estar relacionada à precipitação de fases intermetálicas que prejudicam a resistência à corrosão do aço devido ao empobrecimento de cromo e molibdênio das regiões adjacentes à sua formação. Desse modo há uma diferença entre o máximo de densidade de corrente de ativação (ia) e o máximo de densidade de corrente de reativação (ir). A razão entre ir e ia é definido como grau de sensitização (GS).

\footnotetext{
* Contribuição técnica ao $69^{\circ}$ Congresso Anual da ABM - Internacional e ao 14ํㅡㄹ ENEMET - Encontro Nacional de Estudantes de Engenharia Metalúrgica, de Materiais e de Minas,21 a 25 de julho de 2014, São Paulo, SP, Brasil.
} 
Desse modo o objetivo desse trabalho consiste no estudo do grau de sensitização do aço UNS $\mathrm{S} 31803$ envelhecido a $700^{\circ} \mathrm{C}$ por ensaios de reativação potenciodinâmica de duplo loop (DL-EPR).

\section{MATERIAIS E MÉTODOS}

O material de estudo foi adquirido como chapa de $3 \mathrm{~mm}$ de espessura laminada a $1100^{\circ}$ e resfriada com jato de água e ar forçado. A composição química segue descrita na Tabela 1.

Tabela 1. Composição química (\% em massa) do aço em estudo

\begin{tabular}{|l|c|c|c|c|c|c|c|c|c|c|c|c|c|}
\hline Elemento & $\mathrm{Cr}$ & $\mathrm{Ni}$ & $\mathrm{Mo}$ & $\mathrm{Mn}$ & $\mathrm{N}$ & $\mathrm{C}$ & $\mathrm{Si}$ & $\mathrm{Cu}$ & $\mathrm{Co}$ & $\mathrm{P}$ & $\mathrm{S}$ & $\mathrm{Nb}$ & $\mathrm{Fe}$ \\
\hline$\%$ massa & 22,48 & 5,74 & 3,2 & 1,42 & 0,162 & 0,018 & 0,35 & 0,15 & 0,07 & 0,019 & 0,001 & 0,006 & $\mathrm{Bal}$ \\
\hline
\end{tabular}

A partir do material como recebido foram selecionadas amostras para o tratamento térmico de solubilização a $1175^{\circ} \mathrm{C}$ por $30 \mathrm{~min}$, e resfriamento rápido em água para assegurar uma estrutura homogênea de ferrita e austenita. Em seguida as amostras foram envelhecidas a $700^{\circ} \mathrm{C}$ entre $10 \mathrm{~min}$ e $360 \mathrm{~h}$ em um forno tubular sob atmosfera de $\mathrm{N}_{2}$ para evitar oxidação excessiva.

Antes de realizar o embutimento, todas as superfícies das amostras foram lixadas até a granulometria de 100 mesh para remoção a camada de óxido formada durante a solubilização e envelhecimento, o que poderia prejudicar os ensaios eletroquímicos que seriam realizados posteriormente. Após esse processo as amostras foram embutidas em resina termofixa de cura a quente (baquelite), de modo que a área de estudo corresponde à seção longitudinal com aproximadamente $0,5 \mathrm{~cm}^{2}$ de área. Os corpos de prova foram lixados até 600 mesh e em seguida foram polidos com acabamento final de $1 \mu \mathrm{m}$.

A fração volumétrica de ferrita $(\% \alpha)$ foi obtida com auxílio de ferritoscópio FISCHER modelo MP30 calibrado com o auxílio de padrões, tendo como limite de detecção $0,1 \%$ de ferrita. Vinte medições foram realizadas em cada uma das séries de amostras. Já a identificação e a quantificação das fases intermetálicas formadas foi feita a partir de imagens de elétrons retroespalhados obtidas com Microscópio CamScan CS3200 utilizando para todas as imagens: tensão de aceleração aplicada ao feixe de elétrons, mantida em $20 \mathrm{kV}$; ajuste da corrente elétrica emitida pelo filamento, mantida em $100 \mu \mathrm{A}$; diâmetro de feixe (spot size) constante; distância de trabalho, mantida em $20 \mathrm{~mm}$; e manutenção de valores constantes de brilho e contraste das imagens. A quantificação das fases foi realizada com auxílio software de análise de imagens Olympus Analysis Doku a partir de 5 imagens de elétrons retroespalhados para cada condição de envelhecimento, onde foram quantificadas as fases sigma e chi. A fração de austenita foi obtida seguindo a Equação (1).

$$
\% \gamma=100-\% \alpha-\% \sigma-\% \chi
$$

Os ensaios DL-EPR foram realizados com auxilio do potenciostato AUTOLAB 12 do CDMatM - FEl (Figura 7) usando solução $2 \mathrm{M} \mathrm{H} 2 \mathrm{SO} 4+0,5 \mathrm{NaCl}+0,01 \mathrm{KSCN}$ de acordo com a norma que foi anteriormente testada para o aço em estudo trabalho por Morais [4] e Lopez [7]. O ensaio foi conduzido a 30ํㅡ utilizando como eletrodo de referência o eletrodo de calomelano saturado (ECS), como contra eletrodo foi usada uma barra de platina de área exposta de pelo menos três vezes maior do que a do eletrodo de trabalho. O eletrodo de trabalho são as amostras polidas até

\footnotetext{
* Contribuição técnica ao $69^{\circ}$ Congresso Anual da ABM - Internacional e ao 14ํㅡㄹ ENEMET - Encontro Nacional de Estudantes de Engenharia Metalúrgica, de Materiais e de Minas,21 a 25 de julho de 2014, São Paulo, SP, Brasil.
} 


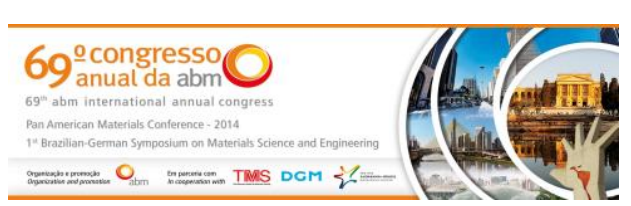

última se forme preferencialmente pela primeira. Observa-se ainda o aumento de chi até $6 \mathrm{~h}$ de envelhecimento, seguido de consumo após esse tempo. A austenita por sua vez tem sua fração volumétrica aumentada até $72 \mathrm{~h}$ de envelhecimento a $700^{\circ} \mathrm{C}$, esse aumento de austenita pode estar relacionado à formação de austenita secundária decorrente do empobrecimento em $\mathrm{Cr}$ e Mo (elementos alfagênicos) da ferrita.

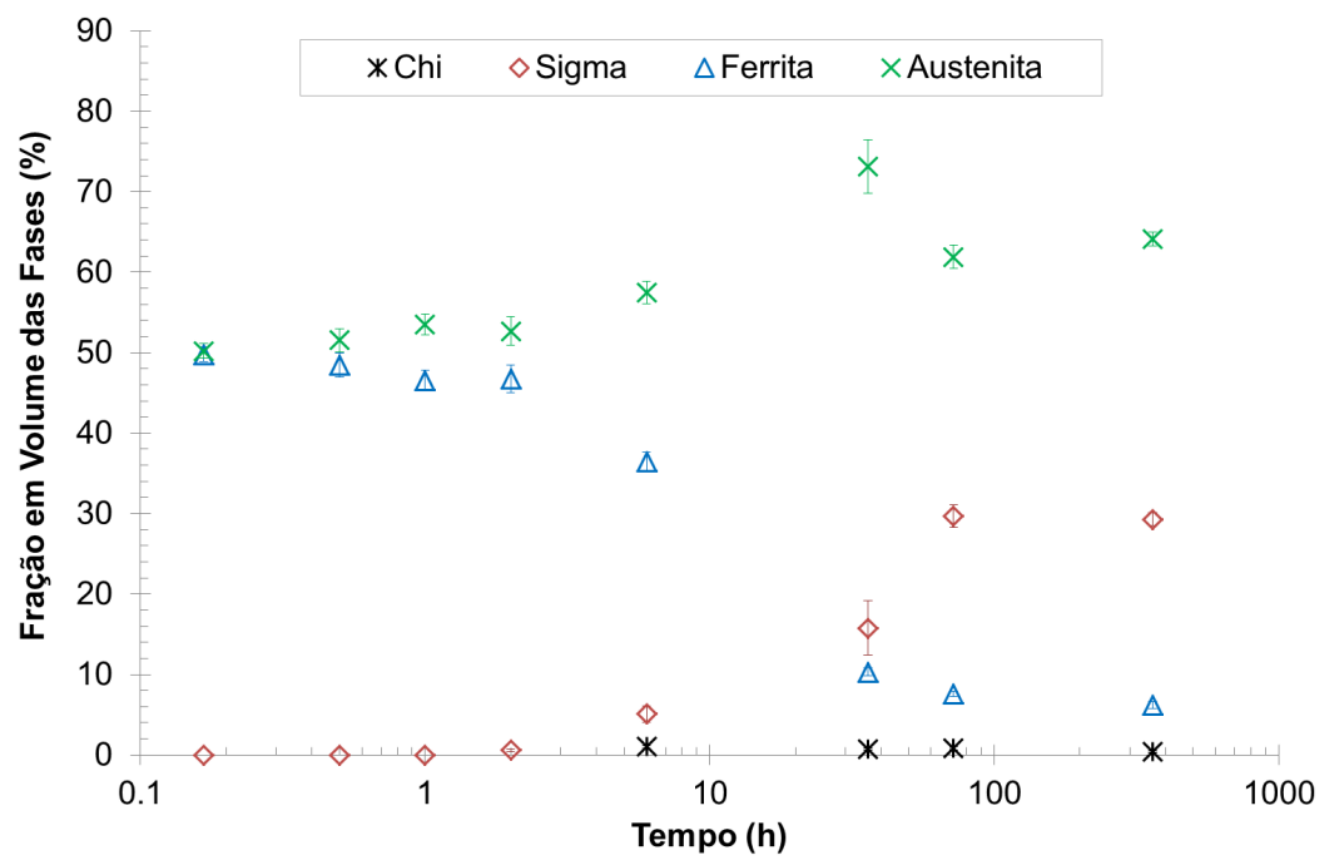

Figura 2. Fração volumétrica de todas as fases em função do tempo de envelhecimento a $700^{\circ} \mathrm{C}$.

Até $2 \mathrm{~h}$ de envelhecimento observa-se o aumento de austenita e consumo de ferrita e não é observada formação de sigma. O que se sugere é que no início do envelhecimento ocorra o reequilíbrio entre ferrita e austenita, anteriormente à formação de sigma. De 2 até $72 \mathrm{~h}$ nota-se um crescente aumento na fração de sigma paralelamente à diminuição na fração de ferrita e um aumento de austenita, isso sugere que sigma está sendo formada por decomposição eutetóide a partir da ferrita, dando origem a sigma e austenita secundária. Após 72 h de envelhecimento a ferrita já foi quase que totalmente consumida, há uma diminuição na fração de austenita e sigma continua a crescer, o que sugere a sigma está se formando neste trecho também a partir da austenita. A diminuição de chi após o começo da formação de sigma sugere ainda que a fase chi serviu como núcleo heterogêneo para formação de sigma e depois foi dissolvida.

A seguir estão apresentadas as curvas obtidas através de ensaios eletroquímicos DL-EPR. As curvas típicas para cada tempo de envelhecimento estão representadas $\mathrm{Na}$ Figura 3. A solução usada para os ensaios foi $\mathrm{H}_{2} \mathrm{SO}_{4}+0,5 \mathrm{M} \mathrm{NaCl}+0,01 \mathrm{M}$ $\mathrm{KSCN}$ a $30^{\circ} \mathrm{C}$.

\footnotetext{
* Contribuição técnica ao 69ำ Congresso Anual da ABM - Internacional e ao 14ํㅡㄹ ENEMET - Encontro Nacional de Estudantes de Engenharia Metalúrgica, de Materiais e de Minas,21 a 25 de julho de 2014, São Paulo, SP, Brasil.
} 

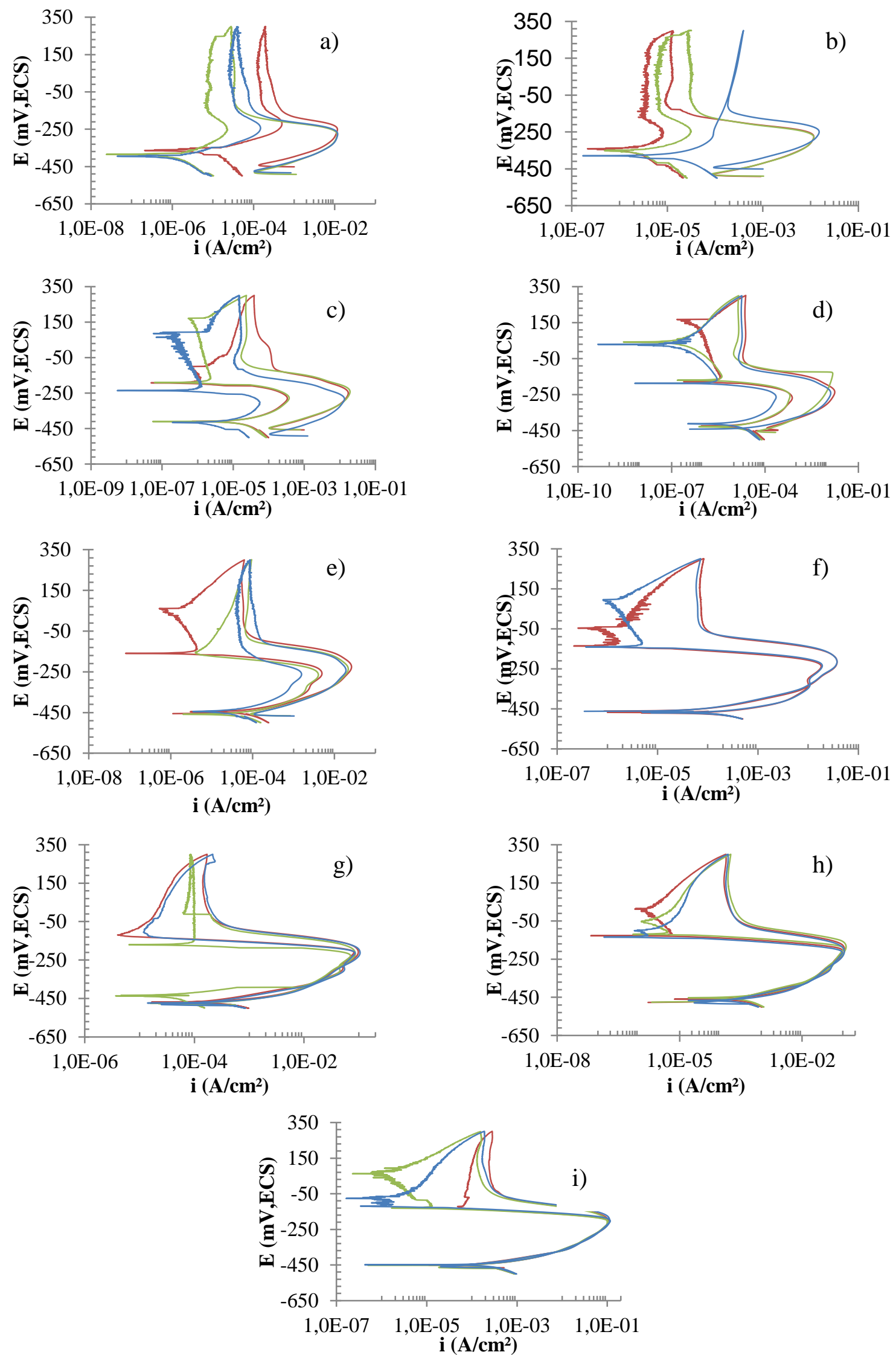

Figura 3. Curvas obtidas por DL-EPR das amostras envelhecidas a $700^{\circ} \mathrm{C}$ por: a)Solubilizadas; b) 10 min. c)30 min. d) 1 h. e)2 h. f)6 h. g)36 h. h)72 h. i)360 h.

* Contribuição técnica ao $69^{\circ}$ Congresso Anual da ABM - Internacional e ao 14ํㅡㄹ ENEMET - Encontro Nacional de Estudantes de Engenharia Metalúrgica, de Materiais e de Minas,21 a 25 de julho de 2014, São Paulo, SP, Brasil. 


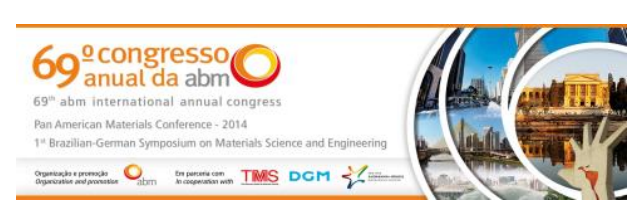

Nota-se que há a formação de dois picos de densidade de corrente tanto na ativação quanto na reação para as amostras entre 2 e $72 \mathrm{~h}$ de envelhecimento, enquanto que as amostras solubilizada, $10 \mathrm{~min}, 30 \mathrm{~min}, 1 \mathrm{~h}$ e $360 \mathrm{~h}$ apresentam apenas um pico de densidade de corrente na ativação e na reativação. Para tempos menores de envelhecimento o potencial de dissolução da austenita e da ferrita é próximo, pois não há precipitação de fases intermetálicas que como foi mencionado, só começa a partir de $2 \mathrm{~h}$ de envelhecimento. Portanto o pico de densidade de corrente da austenita e da ferrita se sobrepõe. Conforme aumentam os tempos de envelhecimento e sigma começa a ser formada, o empobrecimento das regiões adjacentes a sua formação (ferrita) ficam empobrecidas em $\mathrm{Cr}$ e Mo, alterando assim o potencial de dissolução dessa fase, tornando possível diferenciação dos picos de dissolução para austenita e para ferrita. Já para a amostra de 360 h o único pico de densidade de corrente observado é referente à austenita, pois a ferrita já foi quase que totalmente consumida. Os duplos máximos de densidade de corrente registrados estão relacionados à dissolução de ferrita e austenita, conforme mostram trabalhos deste grupo de pesquisa [3-4,8-10].

Por meio das curvas de DL-EPR apresentadas acima foi possível obter os valores do grau de sensitização (GS) dado pela reação entre o máximo de densidade de corrente de ativação em relação ao máximo de densidade de corrente de ativação para a dissolução de cada uma das fases. As curvas da evolução de GS em função do tempo de envelhecimento a $700^{\circ} \mathrm{C}$, tanto da austenita quanto da ferrita estão apresentadas na Figura 4.

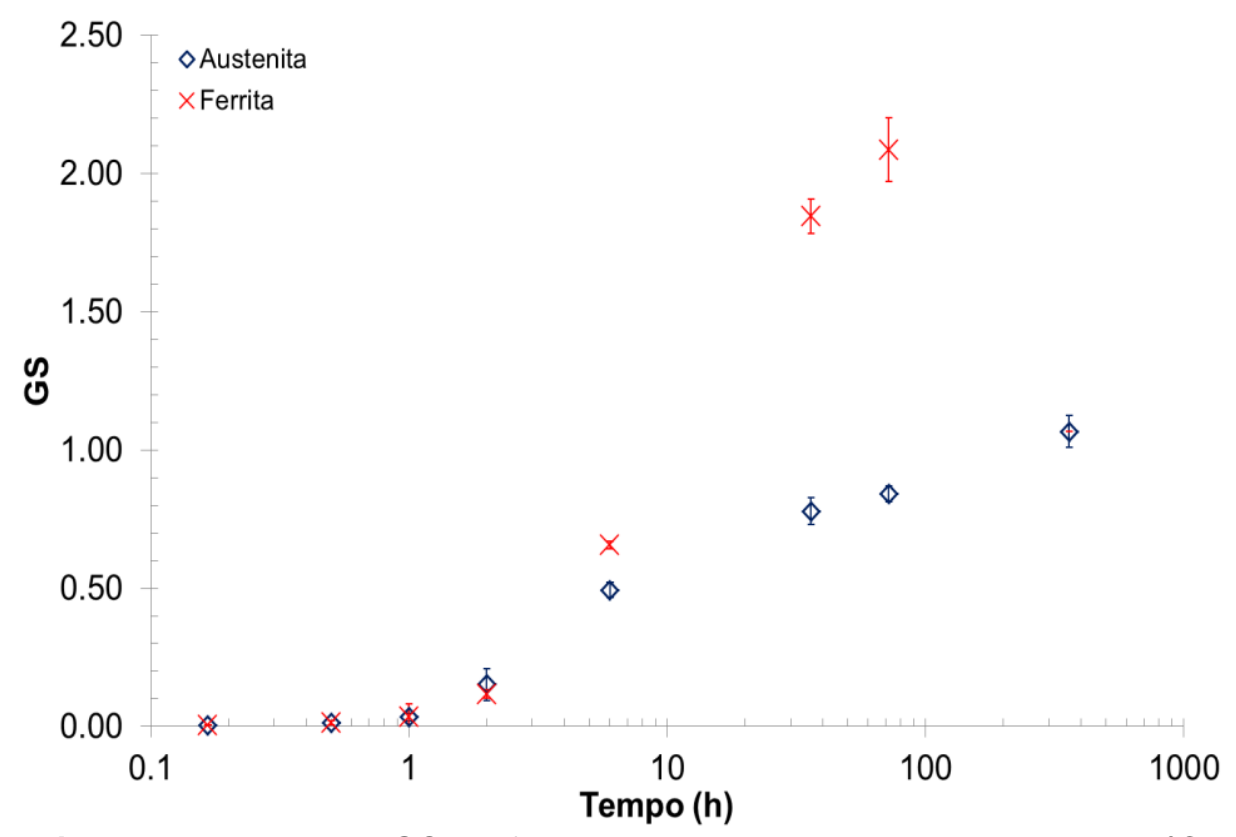

Figura 4. Evolução de GS em função do tempo de envelhecimento a $700^{\circ} \mathrm{C}$.

É possível observar houve aumento no GS de ambas as fases após $1 \mathrm{~h}$ de envelhecimento a $700^{\circ} \mathrm{C}$, já que até $2 \mathrm{~h}$ de envelhecimento o GS da austenita e da ferrita são iguais, pois até então não há transformação de fase e consequentemente os potenciais de dissolução da ferrita e austenita são coincidentes. A partir de $2 \mathrm{~h}$ com a formação de fase sigma e consequente com a formação de fases empobrecidas, os potenciais de dissolução se diferenciam e a ferrita começa a ser mais susceptível à corrosão em relação à austenita. O GS aumenta gradativamente

\footnotetext{
* Contribuição técnica ao $69^{\circ}$ Congresso Anual da ABM - Internacional e ao 14ํㅡㄹ ENEMET - Encontro Nacional de Estudantes de Engenharia Metalúrgica, de Materiais e de Minas,21 a 25 de julho de 2014, São Paulo, SP, Brasil.
} 


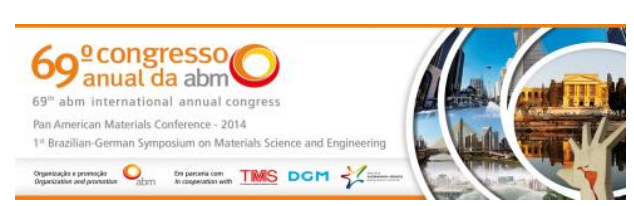

em função do tempo de envelhecimento devido a precipitação de fases intermetálicas conforme aumenta o tempo de envelhecimento. Observa-se ainda que o envelhecimento a $700^{\circ} \mathrm{C}$ por tempos que variam de $10 \mathrm{~min}$ a $360 \mathrm{~h}$ não foi suficiente para promover a redistribuição de cromo e molibdênio para as regiões empobrecidas devido a formação de fases intermetálicas, efeito conhecido como "healing effect", onde ocorre a recuperação do GS em tempos elevados de envelhecimento [4,7].

Após os ensaios eletroquímicos foram feitas imagens das superfícies das amostras envelhecidas por 30 min 6, 36 e 360 h utilizando imagens de elétrons secundários para ter uma noção da evolução das fases ao longo dos tempos de envelhecimento.

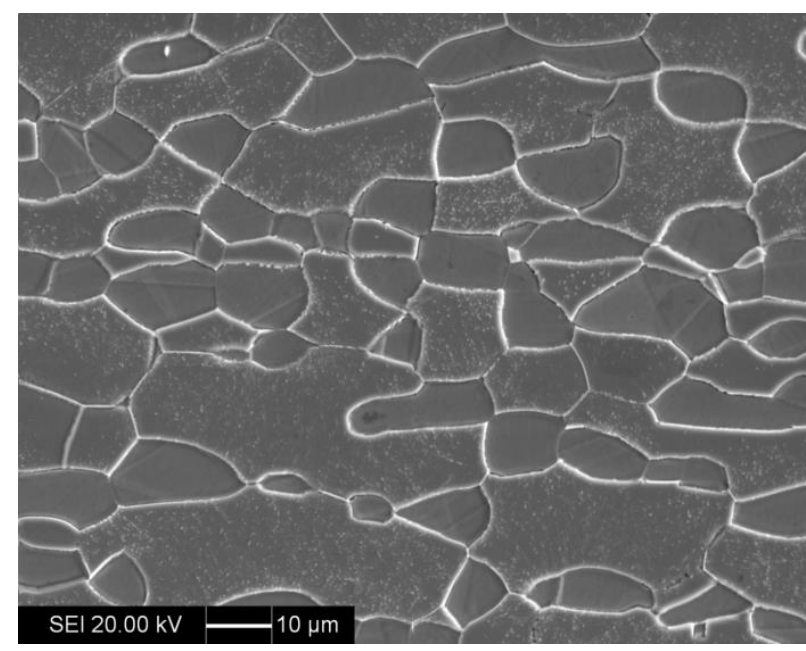

(a)

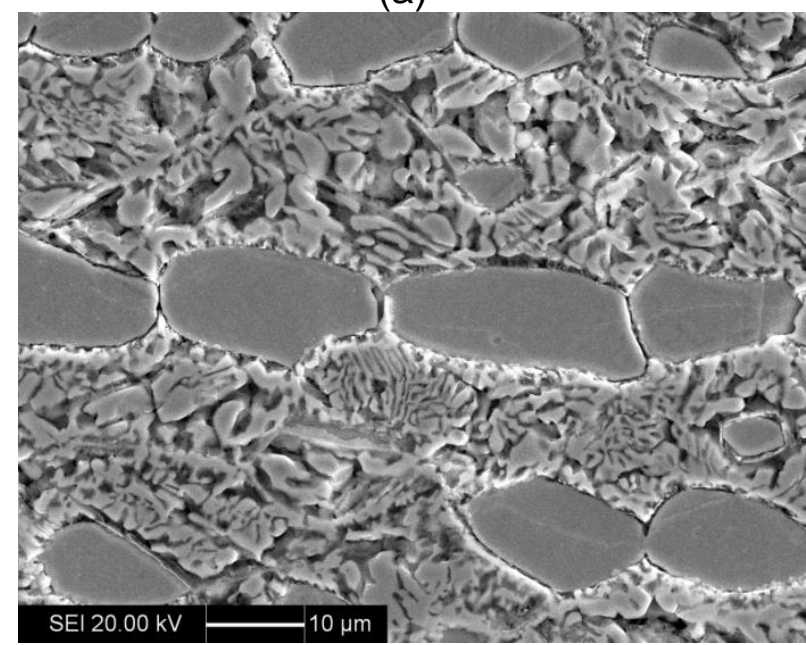

(c)

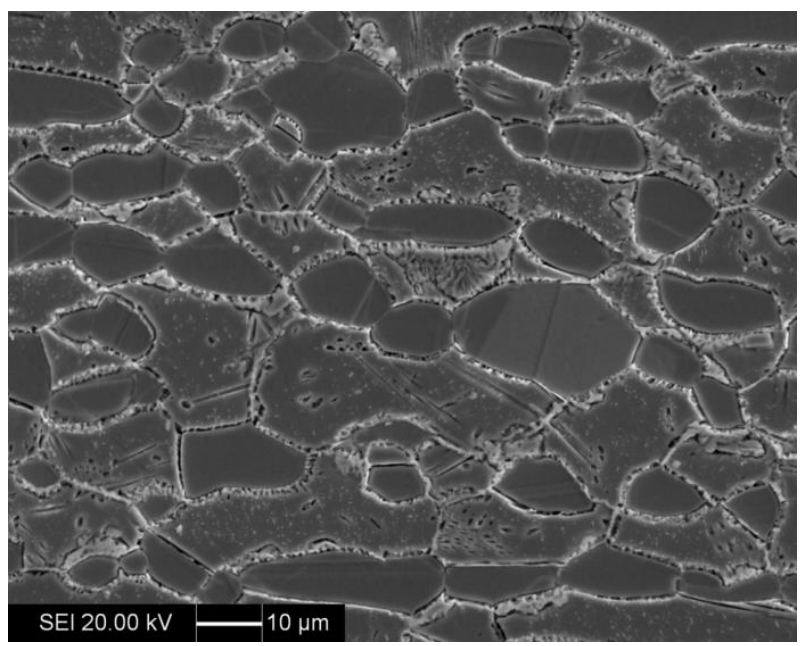

(b)

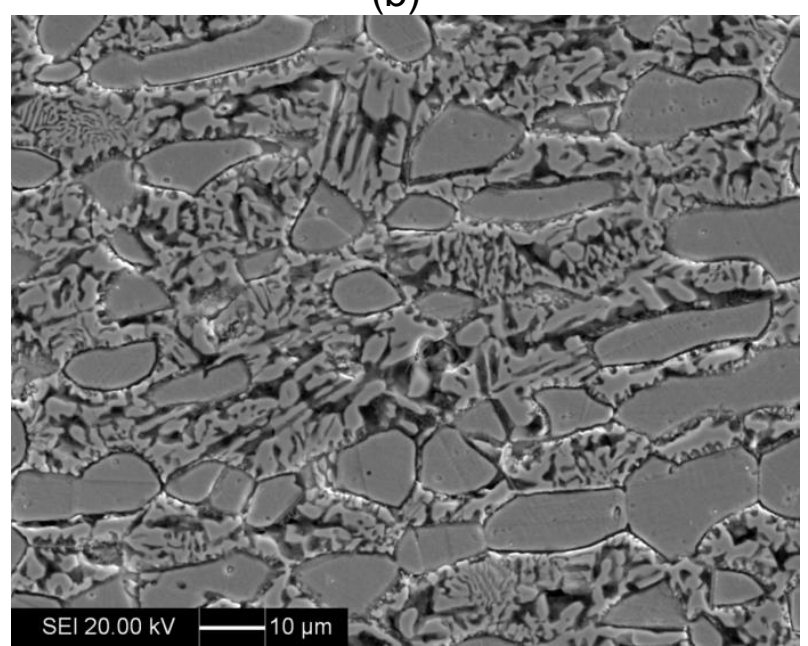

(d)

Figura 5. Imagem elétrons secundários, amostra envelhecida a $700^{\circ} \mathrm{C}$ por: (a) 30 min EPR; (b) $6 \mathrm{~h}$; 36 h; e 360 h após DL-EPR.

Nota-se nas amostras envelhecidas que para a amostra envelhecida por 30 min Figura 5(a) - não há ataque intenso da ferrita e da austenita, pois não há a formação de fases intermetálicas. Já a partir de $6 \mathrm{~h}$ (Figura5 (b)) houve intenso ataque na ferrita Este comportamento confirma a formação da fase sigma preferencialmente a partir da ferrita, tornando a última fase mais empobrecida em $\mathrm{Cr}$ e $\mathrm{Mo}$ e menos resistente a corrosão devido o empobrecimento nestes elementos.

\footnotetext{
* Contribuição técnica ao $69^{\circ}$ Congresso Anual da ABM - Internacional e ao 14ํㅡㄹ ENEMET - Encontro Nacional de Estudantes de Engenharia Metalúrgica, de Materiais e de Minas,21 a 25 de julho de 2014, São Paulo, SP, Brasil.
} 


\section{CONCLUSÃo}

- A formação de sigma se da preferencialmente nas interfaces ferrita/ferrita e ferrita/austenita, com crescimento em direção a ferrita.

- O comportamento eletroquímico do aço UNS S31803 possui forte influência da microestrutura.

- O grau de sensitização aumenta com o aumento na fração de fases intermetálicas e não foi observada recuperação da resistência à corrosão em tempos elevados de envelhecimento pela redistribuição de $\mathrm{Cr}$ e Mo para essas regiões.

- Em tempos de envelhecimento de até $1 \mathrm{~h}$ a $700^{\circ} \mathrm{C}$ o comportamento eletroquímico das fases ferrita e austenita é similar, já que não há formação significativa de fases intermetálicas. A partir desse tempo o grau de sensitização da ferrita é maior em relação à austenita provavelmente devido ao maior empobrecimento em $\mathrm{Cr}$ e Mo dessa fase em virtude da formação de fases intermetálicas.

\section{REFERÊNCIAS}

1 Solomon HD, Devine TMJr. Duplex Stainless Steel: A tale of two phases. In:

Proceedings of the Duplex Stainless Steels; 1982; Ohio, EUA. ASM Metals Park; 1982. p.693-756.

2 Magnabosco R. Kinetics of Sigma Phase Formation in a Duplex Stainless Steel. Materials Research. 2009;12(3):321-327.

3 Santos DC, Magnabosco R, Moura-Neto C. Influence of Sigma Phase Formation on Pitting Corrosion of an Aged UNS S31803 Duplex Stainless Steel. Corrosion. 2013;69(9):900-911.

4 Morais LC. Estudo exploratório do grau de sensitização do aço UNS S311803 envelhecido a $800^{\circ} \mathrm{C}$ por ensaios de reativação potenciodinâmica de duplo loop (DL EPR) [Iniciação científica]. São Bernardo do Campo: Centro Universitário da FEI; 2012.

5 Majidi AP, Streicher MA. The douple loop reactivation method for detecting sensitization in AISI 304 stainless steels. Corrosion. 1984;40(11):584-593.

6 Wolynec S. Técnicas eletroquímicas em corrosão. São Paulo: Editora da Universidade de São Paulo; 2003.

7 Lopez N, Cid M, Puiggali M, Azkarate I, Pelayo A. Application of double loop electrochemical potentiodynamic reactivation test to austenitic and duplex stainless steels. Materials Science and Engineering A. 1997;229:123-128.

8 Santos DC, Magnabosco R. Formação de fases intermetálicas em envelhecimentos rápidos entre 850 e $950^{\circ} \mathrm{C}$ em aço inoxidável superdúplex. In: Anais do 66을 Congresso Anual da ABM; 2011; São Paulo, Brasil. São Paulo: ABM; 2011.

9 Santos DC, Magnabosco R. Influência da formação de sigma no potencial de pite do aço inoxidável duplex UNS S31803 em solução 0,6M NaCl envelhecido a 850 e $900^{\circ} \mathrm{C}$. In: Anais do 65ํㅡㄹ Congresso Anual da ABM; 2010; Rio de Janeiro, Brasil. São Paulo: ABM; 2010.

10 Santos DC, Magnabosco R. Utilização de microscopia eletrônica de varredura na análise quantitativa de fases do aço inoxidável dúplex UNS S31803 envelhecido a 850ㄷ․ In: Anais do 66ํㅡㄹ Congresso Anual da ABM; 2011; São Paulo, Brasil. São Paulo: ABM; 2011.

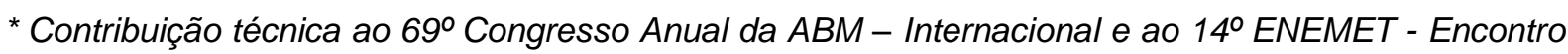
Nacional de Estudantes de Engenharia Metalúrgica, de Materiais e de Minas,21 a 25 de julho de 2014, São Paulo, SP, Brasil.
} 